\title{
ARTICLE OPEN \\ Applying UK real-world primary care data to predict asthma attacks in 3776 well-characterised children: a retrospective cohort study
}

\author{
Steve W Turner (iD) ${ }^{1}$, Clare Murray ${ }^{2,3}$, Mike Thomas ${ }^{4,5}$, Annie Burden ${ }^{6}$ and David B Price (iD ${ }^{6,7}$
}

\begin{abstract}
Current understanding of risk factors for asthma attacks in children is based on studies of small but well-characterised populations or pharmaco-epidemiology studies of large but poorly characterised populations. We describe an observational study of factors linked to future asthma attacks in large number of well-characterised children. From two UK primary care databases (Clinical Practice Research Datalink and Optimum Patient Care research Database), a cohort of children was identified with asthma aged 5-12 years and where data were available for $\geq 2$ consecutive years. In the "baseline" year, predictors included treatment step, number of attacks, blood eosinophil count, peak flow and obesity. In the "outcome" year the number of attacks was determined and related to predictors. There were 3776 children, of whom 525 (14\%) had $\geq 1$ attack in the outcome year. The odds ratio (OR) for one attack was $3.7(95 \%$ Confidence Interval $(\mathrm{Cl}) 2.9,4.8)$ for children with 1 attack in the baseline year and increased to $7.7(95 \% \mathrm{Cl}$ $5.6,10.7)$ for those with $\geq 2$ attacks, relative to no attacks. Higher treatment step, younger age, lower respiratory tract infections, reduced peak flow and eosinophil count $>400 / \mu \mathrm{L}$ were also associated with small increases in OR for an asthma attack during the outcome year. In this large population, several factors were associated with a future asthma attack, but a past history of attacks was most strongly associated with future attacks. Interventions aimed at reducing the risk for asthma attacks could use primary care records to identify children at risk for asthma attacks.
\end{abstract}

npj Primary Care Respiratory Medicine (2018)28:28; doi:10.1038/s41533-018-0095-5

\section{INTRODUCTION}

There are one million children in the United Kingdom with asthma ${ }^{1}$ and six times as many in the United States. ${ }^{2}$ Asthma attacks, characterised by acute cough, wheeze and shortness of breath, are very common and affect approximately $50 \%$ of children with asthma each year. ${ }^{2}$ Asthma attacks result in morbidity and occasionally mortality, and also disrupt both the child's education and their parent's economic activity. At least one-third of healthcare expenditure on childhood asthma is spent managing asthma attacks. ${ }^{3}$ Understandably, preventing asthma attacks is a priority in national asthma guidelines, ${ }^{4-6}$ but there is surprisingly little understood about what factors are associated with future asthma attacks in children.

Good control may be a predictor of future attack, ${ }^{4}$ and many children are not optimally controlled, ${ }^{7}$ but the relationship between current control and future attacks is relatively weak ${ }^{8}$ in part because children are often well controlled for the majority of the time, but develop attacks with rhinovirus infection. Data from clinical trials where participants are well-characterised but relatively small in number find that risk factors for asthma attacks include a recent attack ${ }^{8-10}$ and clinical measurements such as blood eosinophilia, ${ }^{10}$ spirometry (forced expiratory volume in $1 \mathrm{~s}$ $\left.\left(\mathrm{FEV}_{1}\right)\right)^{11}$ and bronchial hyperreactivity. ${ }^{10}$ Other factors associated with future asthma attacks in children include young age, ${ }^{10}$ ethnic group, $^{8}$ obesity $^{12}$ and adherence to asthma medication. ${ }^{13}$ Pharmaco-epidemiology studies of large unselected populations of children but who are not characterised in great detail, find that risk factors for asthma attacks, identified from prescribing or admission data, include recent treatment with oral corticosteroids, ${ }^{14,15}$ recent admission to hospital with asthma, ${ }^{14}$ increased use of bronchodilator medication ${ }^{14}$ and increased asthma severity. ${ }^{15}$ To the best of our knowledge, there are no studies which describe risk factors for future asthma attacks in the United Kingdom, where the healthcare setting is different to many countries. There are also no studies of which we are aware which relate both routinely acquired outcomes (e.g. prescribing) and clinical measurements (e.g. lung function) to risk for future asthma attacks.

Observational studies which use routinely acquired "real-world" data collected in everyday clinical practice give the opportunity to study outcomes in many conditions. ${ }^{16}$ Here we use a large dataset holding routinely acquired patient information to address the question "what factors available in primary care practice can be used to predict asthma attacks in children aged 5-12 years?" Predictive variables included oral corticosteroid treatment for a past attack (this was the definition of an asthma attack in the present study), current control, severity (as evidence by treatment

\footnotetext{
${ }^{1}$ Child Health, University of Aberdeen, Aberdeen, UK; ${ }^{2}$ Centre for Respiratory Medicine and Allergy, Institute of Inflammation and Repair, Manchester Academic Health Science Centre, University Hospital of South Manchester, NHS Foundatin Turst, The University of Manchester, Manchester, UK; ${ }^{3}$ Royal Manchester Children's Hospital, Central Manchester University Hospitals NHS Foundation Trust, Manchester, UK; ${ }^{4}$ Primary Care and Population Sciences, University of Southampton, Southampton, UK; ${ }^{5}$ NIHR Southampton

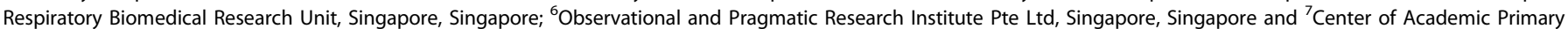
Care, University of Aberdeen, Aberdeen, UK Correspondence: David B Price (dprice@opri.sg)
}

Received: 11 February 2018 Revised: 15 June 2018 Accepted: 18 June 2018 Published online: 23 July 2018 


\section{Combined databases

$$
N=1,531,933
$$

Inclusion criteria:

Patients with asthma diagnosis at any time

Inclusion criteria:

Eosinophil readings ever

Inclusion criteria:

Aged 5-12 years at index date

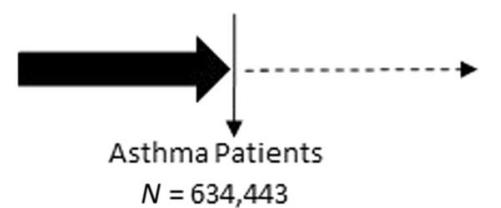

Patients with no asthma diagnosis

$(n=897,490)$

No eosinophil readings recorded

ever $(n=248,746)$

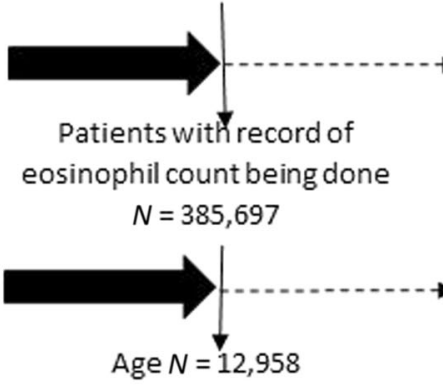

Age $>12$ years or $<5$ years

$(n=372,739)$

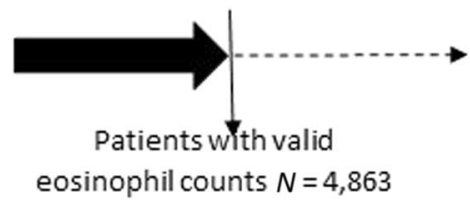

No eosinophil result recorded

Inclusion criteria:

Numeric eosinophil counts

recorded and $\leq 5000 \times 10^{6} / \mathrm{L}$

Inclusion criteria:

Data analysis period defined as: 1 year prior to and 1 year after index date

\section{Inclusion criteria:}

No other chronic respiratory

disease diagnosis ever (inc. COPD)

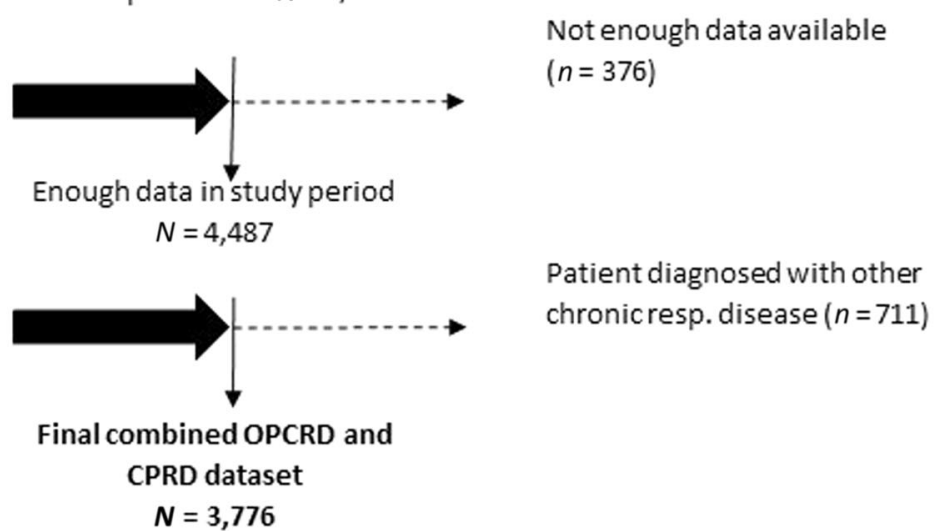

Fig. 1 A consort-style diagram showing how children described in the present study were identified from the whole population. COPD chronic obstructive pulmonary disease

step), age, sex, obesity, peak flow and blood eosinophilia. The latter was included in light of evidence from children ${ }^{17}$ and adults $^{18}$ that eosinophilia is predictive of future asthma attacks. Although the Global INitiative for Asthma (GINA) guideline does not recommend routine measurement of eosinophil count, it does identify eosinophilia as a risk factor for asthma attacks in children aged 6-11 years and adolescents. ${ }^{6}$

\section{RESULTS}

Study subjects

There were 3776 children identified, the mean age was 9.0 years (SD 2.3) and 57\% were male. Figure 1 shows how individuals were identified from the whole population. There were 638 children (16.9\%) with $\geq 1$ attack in the baseline year, of whom 178 had $\geq 2$ attacks in the baseline year. In the outcome year, there were 525 (13.9\%) children with $\geq 1$ attack(s) including 159 (4.2\%) with $\geq 2$ attack(s). Of the 638 patients with $\geq 1$ attack(s) in the baseline year, $240(38 \%)$ had at least one attack during the outcome year. For the 460 patients with exactly one attack in the baseline year, 143
(31\%) had an attack during the outcome year, and for the 178 with $\geq 2$ attacks in the baseline year, there were 97 (54\%) who had one attack in the outcome year. Data were complete for all variables apart from body mass index (data available in 2037 children) and peak expiratory flow (PEF) (data available in 2216). Compared to a population of children from an Optimum Patient Care Research study who met the same inclusion and exclusion criteria except the presence of eosinophil data, the 3776 children in the present study were of similar age and were no more likely to be prescribed short-acting $\beta$-agonists (79 vs. $78 \%$ ), but had a smaller proportion of boys ( 57 vs. $62 \%$ ), were better controlled (74 vs. $61 \%$ ) and were more likely to be prescribed inhaled corticosteroids (70 vs. $65 \%$ ) (see Table 1).

Factors detected in the baseline year associated with attack during the outcome year: univariable analysis

The following factors in the baseline year were associated with increased risk for asthma attack during the outcome year: young age, a history of hayfever diagnosis, a history of eczema diagnosis, eosinophilia, uncontrolled asthma, an asthma attack, consultation 
Table 1. Comparison of children included in the present study with children with asthma in primary care

\begin{tabular}{|c|c|c|}
\hline & $\begin{array}{l}\text { Population in } \\
\text { current study }\end{array}$ & $\begin{array}{l}\text { Reference } \\
\text { population }\end{array}$ \\
\hline Mean age (SD), years & $9.0(2.3)$ & $9.0(2.2)$ \\
\hline \multicolumn{3}{|l|}{ Gender } \\
\hline$\%$ Female $(n)$ & $44 \%(1642)$ & $38 \%(4213)$ \\
\hline$\%$ Male $(n)$ & $57 \%(2134)$ & $62 \%(6812)$ \\
\hline \multicolumn{3}{|l|}{ Overall asthma control } \\
\hline$\%$ Controlled $(n)$ & $74 \%(2768)$ & $61 \%(6765)$ \\
\hline$\%$ Uncontrolled $(n)$ & $26 \%(1008)$ & $39 \%(4265)$ \\
\hline \multicolumn{3}{|l|}{ Daily SABA dosage $(\mu \mathrm{g})$} \\
\hline$\%$ on no SABA $(n)$ & $21 \%(777)$ & $22 \%(2381)$ \\
\hline$\%$ prescribed $1-100(n)$ & $12 \%(465)$ & $51 \%(5572)$ \\
\hline$\%$ prescribed $101-200(n)$ & $28 \%(1064)$ & $20 \%(2180)$ \\
\hline$\%$ prescribed $201-300(n)$ & $17 \%(647)$ & $5 \%(533)$ \\
\hline$\%$ prescribed $301+(n)$ & $22 \%(823)$ & $3 \%(364)$ \\
\hline \multicolumn{3}{|l|}{$\begin{array}{l}\text { Average ICS daily dose (BUD } \\
\text { equivalent) }(\mu \mathrm{g})\end{array}$} \\
\hline$\%$ prescribed none $(n)$ & $30 \%(1134)$ & $35 \%(3822)$ \\
\hline$\%$ prescribed $<100(n)$ & $24 \%(916)$ & $29 \%(3234)$ \\
\hline$\%$ prescribed 101-200 $(n)$ & $22 \%(812)$ & $20 \%(2217)$ \\
\hline$\%$ prescribed $>200(n)$ & $24 \%(914)$ & $16 \%(1757)$ \\
\hline \multicolumn{3}{|c|}{$\begin{array}{l}\text { Inclusion criteria for the reference population were doctor diagnosis of } \\
\text { asthma at any time (recorded as a Read code), } 1 \text { continuous year of } \\
\text { practice data preceding the index date and atleast one prescription for } \\
\text { asthma therapy within the } 2 \text { years preceding the index date (SABA, ICS, } \\
\text { LABA, ICS/LABA combinations, LTRA). Patients were excluded if their record } \\
\text { contained an asthma-resolved Read code or a Read code for COPD or any } \\
\text { chronic respiratory disease other than asthma The index date for each } \\
\text { patient was defined as the date of data extraction for their general } \\
\text { practice. Data for each patient were assessed for } 1 \text { year preceding their } \\
\text { index date (the study year); the full period of study ran from } 27 \text { January } \\
2009 \text { to } 21 \text { March } 2013\end{array}$} \\
\hline
\end{tabular}

for lower respiratory tract infection, increased use of reliever medication, higher dose of inhaled corticosteroid and more severe asthma (as evidenced by Global Initiative for Asthma (GINA) treatment step) (Table 2). A PEF measurement was obtained during the baseline year for 2216 children (58.7\% of the cohort) and the mean (SD) PEF reading for 1878 children with no subsequent asthma attack was $103 \%$ (26) and for the 338 with $\geq 1$ subsequent asthma attack was $99 \%$ (28), $p=0.020$ (Table 2). Sex and obesity were not associated with altered risk for asthma attacks (Table 2).

\section{Multivariable analysis}

In the multivariable analysis a higher GINA management step, having any consultation for lower respiratory tract infection, an asthma attack, the presence of eosinophilia and younger age were independently associated with increased risk for asthma attack during the outcome year (Table 3). The \% expected PEF was also predictive of asthma attack in the multivariable analysis of the sub-group of patients with these data available (odds ratio (OR) (95\% confidence interval (Cl)) $0.995(0.990,1.000), p=0.036)$ (Table 4).

\section{DISCUSSION}

Asthma attacks are common in children and potentially preventable, and this study was designed to relate a comprehensive number of factors, which are readily available in primary care, to
Table 2. Risk predictors from univariable analysis for at least one asthma attack defined by American Thoracic Society criteria

\begin{tabular}{|c|c|c|c|c|}
\hline & \multicolumn{2}{|c|}{$\begin{array}{l}\text { Number of future } \\
\text { attacks }\end{array}$} & \multirow[t]{2}{*}{ Total } & \multirow[t]{2}{*}{$p$ Value } \\
\hline & $\overline{0}$ & $\geq 1$ & & \\
\hline Mean age (SD), years & $9.0(2.3)$ & $8.6(2.4)$ & $9.0(2.3)$ & $<0.001^{\mathrm{b}}$ \\
\hline \multicolumn{5}{|l|}{ Age group } \\
\hline $5-6$ years, $n(\%)$ & 605 (18.6) & $139(26.5)$ & $744(19.7)$ & \multirow[t]{3}{*}{$<0.001^{b}$} \\
\hline $7-10$ years, $n(\%)$ & $1559(48)$ & $244(46.5)$ & $1803(47.7)$ & \\
\hline $11-12$ years, $n(\%)$ & $1087(33.4)$ & $142(27)$ & $1229(32.5)$ & \\
\hline \multicolumn{5}{|l|}{ Gender } \\
\hline Female, $n(\%)$ & $1407(43.3)$ & $235(44.8)$ & $1642(43.5)$ & \multirow[t]{2}{*}{$0.525^{\mathrm{b}}$} \\
\hline Male, $n(\%)$ & $1844(56.7)$ & $290(55.2)$ & $2134(56.5)$ & \\
\hline \multicolumn{5}{|l|}{ IOTF grade } \\
\hline Thin, $n(\%)$ & $279(16.5)$ & $53(15.5)$ & $332(16.3)$ & \multirow[t]{4}{*}{$0.941^{b}$} \\
\hline Normal, $n(\%)$ & $929(54.8)$ & $191(55.7)$ & $1120(55)$ & \\
\hline Overweight, $n$ (\%) & $303(17.9)$ & $60(17.5)$ & $363(17.8)$ & \\
\hline Obese, $n(\%)$ & $183(10.8)$ & $39(11.4)$ & $222(10.9)$ & \\
\hline \multicolumn{5}{|l|}{ Hayfever diagnosis ever } \\
\hline Yes, $n(\%)$ & $995(30.6)$ & $189(36.0)$ & $1184(31.4)$ & \multirow[t]{2}{*}{$0.013^{b}$} \\
\hline No, $n(\%)$ & $2256(69.4)$ & $336(64.0)$ & $2592(68.6)$ & \\
\hline \multicolumn{5}{|l|}{ Eczema diagnosis ever } \\
\hline Yes, $n(\%)$ & $1831(56.3)$ & $339(64.4)$ & $2170(57.5)$ & \multirow[t]{2}{*}{$<0.001^{\mathrm{t}}$} \\
\hline No, $n$ (\%) & $1420(43.7)$ & $186(35.4)$ & $1606(42.5)$ & \\
\hline \multicolumn{5}{|l|}{ Eosinophil count $\left(\times 10^{9} / \mathrm{L}\right)$} \\
\hline$\leq 0.4, n(\%)$ & $1739(53.5)$ & 225 (42.9) & $1964(52)$ & \multirow[t]{2}{*}{$<0.001^{\mathrm{t}}$} \\
\hline$>0.4, n(\%)$ & $1512(46.5)$ & $300(57.1)$ & $1812(48)$ & \\
\hline \multicolumn{5}{|l|}{ Overall asthma control } \\
\hline Controlled, $n(\%)$ & $2534(77.9)$ & $234(44.6)$ & $2768(73.3)$ & \multirow[t]{2}{*}{$<0.001^{b}$} \\
\hline Uncontrolled, $n$ (\%) & $717(22.1)$ & $291(55.4)$ & $1008(26.7)$ & \\
\hline \multicolumn{5}{|l|}{$\begin{array}{l}\text { Asthma attack in } \\
\text { baseline year }\end{array}$} \\
\hline $0, n(\%)$ & $2853(87.8)$ & $285(54.3)$ & $3138(83.1)$ & \multirow[t]{3}{*}{$<0.001^{b}$} \\
\hline $1, n(\%)$ & $317(9.8)$ & $143(27.2)$ & $460(12.2)$ & \\
\hline$\geq 2, n(\%)$ & $81(2.5)$ & $97(18.5)$ & $178(4.7)$ & \\
\hline \multicolumn{5}{|l|}{$\begin{array}{l}\text { LRTI consultations } \\
\text { resulting in script for } \\
\text { antibiotics }\end{array}$} \\
\hline $0, n(\%)$ & $2910(89.5)$ & $421(80.2)$ & $3331(88.2)$ & \multirow[t]{3}{*}{$<0.001^{b}$} \\
\hline $1, n(\%)$ & $280(8.6)$ & $82(15.6)$ & $362(9.6)$ & \\
\hline $2+, n(\%)$ & $61(1.9)$ & $22(4.2)$ & $83(2.2)$ & \\
\hline \multicolumn{5}{|l|}{ GINA management step } \\
\hline $0, n(\%)$ & $616(18.9)$ & $52(9.9)$ & $668(17.7)$ & $<0.001^{\mathrm{b}}$ \\
\hline $1, n(\%)$ & $395(12.2)$ & $47(9.0)$ & $442(11.7)$ & \\
\hline $2, n(\%)$ & $1726(53.1)$ & $258(49.1)$ & $1984(52.5)$ & \\
\hline $3, n(\%)$ & $381(11.7)$ & $96(18.3)$ & 477 (12.6) & \\
\hline $4, n(\%)$ & $125(3.8)$ & $67(12.8)$ & $192(5.1)$ & \\
\hline $5, n(\%)$ & $8(0.2)$ & $5(1.0)$ & $13(0.3)$ & \\
\hline Daily SABA dosage $(\mu \mathrm{g})$ & & & & \\
\hline None, $n(\%)$ & $715(22.0)$ & $62(11.8)$ & 777 (20.6) & $<0.001^{b}$ \\
\hline $1-100, n(\%)$ & $410(12.6)$ & $55(10.5)$ & $465(12.3)$ & \\
\hline $101-200, n(\%)$ & $925(28.5)$ & $139(26.5)$ & $1064(28.2)$ & \\
\hline $201-300, n(\%)$ & $558(17.2)$ & $89(17.0)$ & $647(17.1)$ & \\
\hline $301+, n(\%)$ & $643(19.8)$ & $180(34.3)$ & $823(21.8)$ & \\
\hline $\begin{array}{l}\text { Average ICS daily } \\
\text { (BUD equivalent) }\end{array}$ & & & & \\
\hline
\end{tabular}




\begin{tabular}{|c|c|c|c|c|}
\hline & \multicolumn{2}{|c|}{$\begin{array}{l}\text { Number of future } \\
\text { attacks }\end{array}$} & \multirow[t]{2}{*}{ Total } & \multirow[t]{2}{*}{$p$ Value } \\
\hline & 0 & $\geq 1$ & & \\
\hline None, $n(\%)$ & $1032(31.7)$ & $102(19.4)$ & $1134(30.0)$ & $<0.001$ \\
\hline$<100, n(\%)$ & $796(24.5)$ & $120(22.9)$ & $916(24.3)$ & \\
\hline $101-200, n(\%)$ & $708(21.8)$ & 104 (19.8) & $812(21.5)$ & \\
\hline$>200, n(\%)$ & $715(22)$ & 199 (37.9) & $914(24.2)$ & \\
\hline \multicolumn{5}{|l|}{$\begin{array}{l}\text { Percent predicted peak } \\
\text { flow readings (\%) }\end{array}$} \\
\hline$N(\%$ non-missing) & $1878(57.8)$ & $338(64.4)$ & $2216(58.7)$ & $0.020^{\mathrm{a}}$ \\
\hline Mean (SD) & $\begin{array}{l}102.89 \\
(25.53)\end{array}$ & $\begin{array}{l}99.06 \\
(28.24)\end{array}$ & $\begin{array}{l}102.30 \\
(25.99)\end{array}$ & \\
\hline Median (IQR) & $\begin{array}{l}101.1 \\
(86.2, \\
117.7)\end{array}$ & $\begin{array}{l}98.3(79.5 \\
117.3)\end{array}$ & $\begin{array}{l}100.6 \\
(84.8 \\
117.6)\end{array}$ & \\
\hline $\begin{array}{l}\text { Median year at start of } \\
\text { outcome years (IQR) }\end{array}$ & $\begin{array}{l}2007 \\
(2005, \\
2008)\end{array}$ & $\begin{array}{l}2007 \\
(2005, \\
2008)\end{array}$ & $\begin{array}{l}2007 \\
(2005, \\
2008)\end{array}$ & $0.257^{\mathrm{b}}$ \\
\hline $\begin{array}{l}\text { IOTF International Obesit } \\
\text { LRTI lower respiratory tra } \\
{ }^{a} t \text { test } \\
{ }^{b} X^{2} \text { test }\end{array}$ & $\begin{array}{l}\text { Task Force } \\
\text { infection }\end{array}$ & GINA Globa & INitiative for & Asthma \\
\hline
\end{tabular}

Table 3. Risk predictors for at least one asthma attack defined by the American Thoracic Society criteria

\begin{tabular}{|c|c|c|c|c|}
\hline $\begin{array}{l}\text { Reference } \\
\text { category }\end{array}$ & Comparison & $\begin{array}{l}\text { Odds ratio } \\
(95 \% \mathrm{Cl})\end{array}$ & $\begin{array}{l}p \\
\text { Value }\end{array}$ & $\begin{array}{l}\text { Overall } p \\
\text { value }\end{array}$ \\
\hline \multicolumn{5}{|l|}{$\begin{array}{l}\text { Blood eosinophil } \\
\text { count }\end{array}$} \\
\hline$\leq 400 / \mu \mathrm{L}$ & $>400 / \mu \mathrm{L}$ & $1.46(1.20,1.78)$ & $<0.001$ & $<0.001$ \\
\hline \multicolumn{5}{|l|}{$\begin{array}{l}\text { GINA management } \\
\text { step }\end{array}$} \\
\hline \multirow[t]{3}{*}{0} & $1 / 2$ & $1.17(0.85,1.62)$ & 0.331 & $<0.001$ \\
\hline & 3 & $1.80(1.23,2.64)$ & 0.003 & \\
\hline & $4 / 5$ & $2.77(1.77,4.33)$ & $<0.001$ & \\
\hline \multicolumn{5}{|l|}{$\begin{array}{l}\text { GP consults for } \\
\text { LRTIs }\end{array}$} \\
\hline 0 & $1+$ & $1.50(1.15,1.96)$ & 0.003 & 0.003 \\
\hline \multicolumn{5}{|l|}{ Asthma attack } \\
\hline \multirow[t]{2}{*}{0} & 1 & $3.74(2.92,4.80)$ & $<0.001$ & $<0.001$ \\
\hline & $2+$ & $\begin{array}{l}7.72(5.55 \\
10.74)\end{array}$ & $<0.001$ & \\
\hline \multicolumn{5}{|l|}{ Age } \\
\hline Per year of age & & $0.93(0.89,0.97)$ & 0.001 & \\
\hline \multicolumn{5}{|c|}{$\begin{array}{l}\text { The results are from a multivariable analysis. The following variables were } \\
\text { significantly associated with asthma attack in the univariate analyses but } \\
\text { were not significant in the multivariate model: hayfever diagnosis ever, } \\
\text { eczema diagnosis ever, overall asthma control, daily short-acting } \beta \text {-agonist } \\
\text { dosage and average inhaled corticosteroid daily dose. } \\
\text { GINA Global INitiative for Asthma, } L R T I \text { lower respiratory tract infection }\end{array}$} \\
\hline
\end{tabular}

the risk for future asthma attacks in children aged 5-12 years. Our study considered the largest number of factors previously described and used a relatively large "real-world" population. We are not aware of another published material which describes asthma attack outcomes in a UK population. Our results indicate that, of all the outcomes collected in this large study, a past asthma attack (and especially two attacks) is likely to be the best method to identify children who might benefit from a stratified intervention aimed at reducing their risk for future asthma attacks.

Factors other than a past history of attacks which were associated with increased risk for future asthma attacks included blood eosinophilia, reduced PEF, lower respiratory tract infection and younger age, and although these associations were highly significant, they were weakly related to risk for asthma attacks and therefore not likely to be particuarly helpful in risk analysis. Current asthma control (as evidenced by short-acting $\beta$-agonist use) was related to future asthma attacks in univariable analysis but not in the multivariable analysis, and this challenges the paradigm that in children current control is a useful predictor of future attacks. ${ }^{4}$

The majority of the literature describing factors predictive of asthma attacks in children is based on US populations where the healthcare system is very different to the United Kingdom, but the findings of the current study are nonetheless comparable with the US literature. For example, in a secondary analysis of data in 285 6-14-year-old trial participants, Covar et al. ${ }^{9}$ found that those who received a course of oral corticosteroids for an asthma attack were at a twofold increased risk of an attack in the following year. A large database study of 16,250 children with asthma also found a twofold increase in risk for an attack in the year after a previous attack. ${ }^{14}$ In a cohort of 563 6-11 year olds with severe or difficultto-treat asthma, Haselkorn et al. ${ }^{8}$ report that an attack in the previous 6 months was associated with a threefold increased risk for future attack. Finally, a study of 14,303 children with asthma living in the Netherlands also found that a past attack was the strongest predictor of future attack. ${ }^{15}$

In contrast with the consistent literature describing the relationship between past and future asthma attacks in children, the relationship between asthma control and future attacks is much less consistent. In our study asthma control (as evidenced by use of short-acting $\beta$-agonist) was associated with increased risk for attack in the univariable analysis, but this relationship was not seen in the multivariable analysis, perhaps due to being subsumed by treatment step. Using more than three SABA canisters was associated with a $50 \%$ increased risk for future attack in the large database study previously described ${ }^{14}$, but a relationship between asthma control (determined by the Children's Asthma Control Test) and future attacks was only present in one of two other studies. ${ }^{9,19}$ A disconnect between asthma control and attack may be explained by different underlying factors, for example, a rhinovirus infection may commonly lead to an asthma attack, ${ }^{20}$ but is not likely to lead to poor control outside the setting of an attack.

In our study blood eosinophilia at the index date was associated with increased odds for an asthma attack in the following year, but the magnitude of the increase was small and is consistent with a study of $3335-11$ year olds (OR 1.52) ${ }^{17}$ and $12-80$ year olds (OR $1.48),{ }^{18}$ and this suggests a common but weak association between blood eosinophilia and future asthma attacks between ages 5 and 80 years. We do not believe that blood eosinophilia should be considered as part of any routine asthma review in children, but some subgroups (e.g. those with multiple allergies) may benefit from eosinophil monitoring.

Our study observed a link between reduced PEF and increased risk of future asthma attack, but the magnitude of the association was very small. Whilst PEF monitoring is still widely used, current guidelines do not support its routine use ${ }^{4}$ and there is good evidence that routine PEF monitoring does not improve asthma control. $^{21}$ There are other objective measures such as $\mathrm{FEV}_{1}{ }^{22}$ fractional exhaled nitric oxide ${ }^{23}$ and exhaled breath condensate ${ }^{19}$ which may be useful in predicting asthma attacks in children, but further evaluation of these measurements are required before they can be routinely applied. 
Table 4. Multivariable analysis of the sub-group of patients with PEF data available describing risk predictors for at least one asthma attack defined by the American Thoracic Society criteria

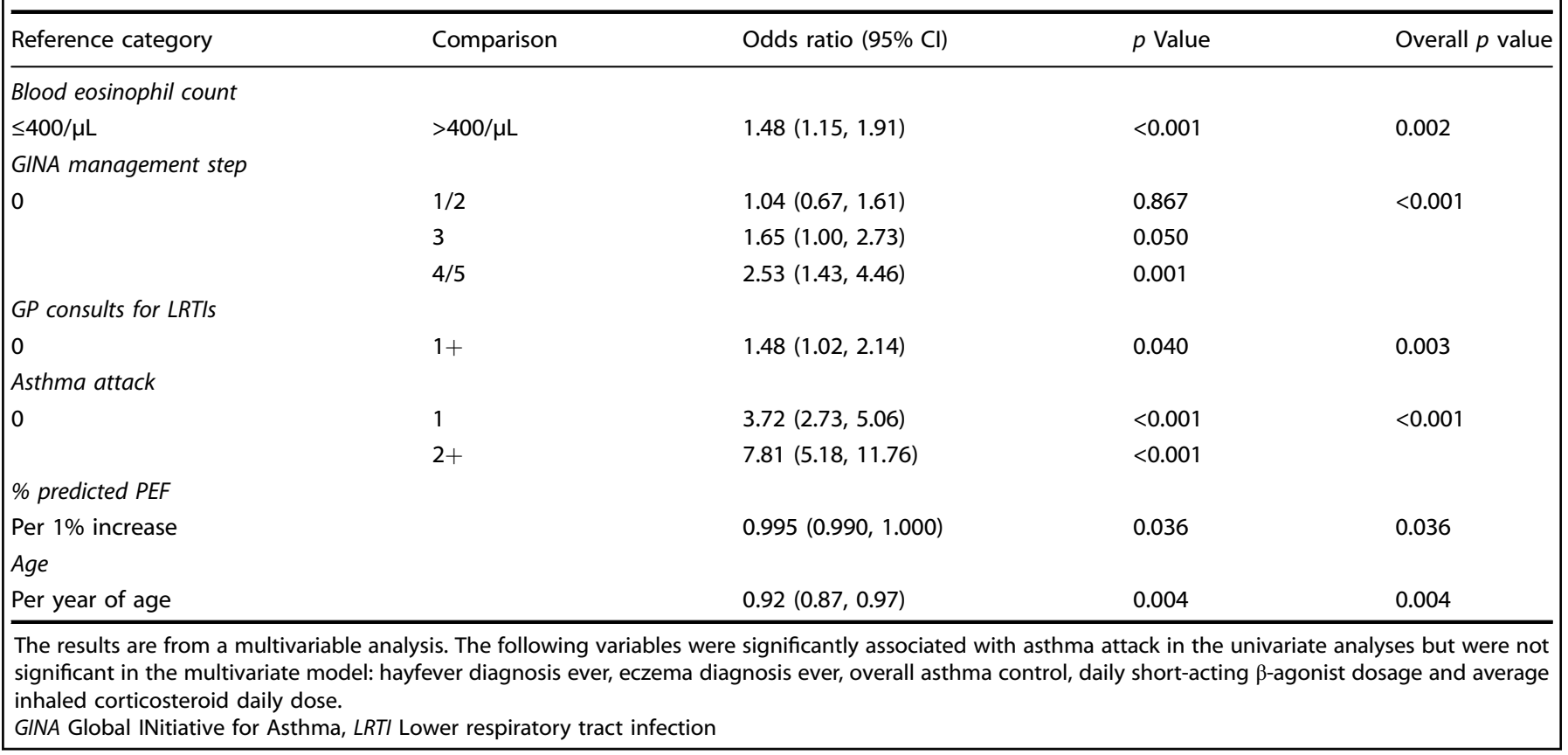

When interpreting our data it is important to note that not all children with asthma have their blood eosinophil count measured and although we have demonstrated that the participants in this study had only relatively minor differences when compared to a population of asthmatic children in UK primary care, our results are likely to be generalisable. The children included in this analysis had a very similar burden of past asthma attacks compared to other populations. ${ }^{24,25}$ What we do not know is why the blood eosinophilia is being checked; if blood was taken during an asthma attack, then the relationship between blood eosinophilia and future attack may be confounded by the very presence of the initial attack, and this might strengthen any association between blood eosinophilia and future attacks, but as we have previously stated, the magnitude of this association was small and of limited clinical relevance.

A limitation to our study is that we were not able to include an index of adherence in our analysis and poor adherence is a potentially modifiable risk factor for an asthma attack. A second limitation is that we did not have an index of asthma control and we inferred control status from short-acting $\beta$-agonist prescription use. A further limitation is that data for PEF and obesity were missing for a minority of children and this may have reduced the power of the analysis, but we do not believe that these missing data have substantially affected the results since the observed associations between PEF and obesity and asthma attacks were respectively weak and non-significant.

In summary, we find that a past history of asthma attacks is the best predictor of future attacks, and that blood eosinophilia and reduced PEF do not add substantially to predicting attacks. Current guidelines ${ }^{4}$ recommend that a review in primary care within two working days of discharge from hospital should include checking inhaler technique, reviewing the asthma action plan and modify treatment if required, and a similar intervention could be applied after an asthma attacks not requiring hospitalisation. Research is now required to determine whether an early review after an asthma attack could reduce future asthma attacks.

\section{METHODS}

Study design

This was a historic observational cohort study using data from the Clinical Practice Research Datalink (CPRD, https://www.cprd.com/home/) and Optimum Patient Care Research Database (OPCRD, http:// optimumpatientcare.org/opcrd/). The use of data was approved by the Independent Scientific Advisory Committee of the CPRD and the Trent Multi-Centre Research Ethics Committee. A steering committee was involved in a priori definition of the study methodology (including statistical analysis plan), review of analyses and interpretation of results. Data collected during a 12-month period ("baseline year") were linked to asthma attacks during the following years (the "outcome year"). The index date (i.e. the start of the outcome year) was the date when blood eosinophil count was determined. Variables that were linked to risk of future asthma attack were selected since they have previously been associated with asthma attacks in children; also, all but eosinophil count and peak flow have been associated with the need for more troublesome asthma (as evidenced by treatment requirement) in this population. ${ }^{26}$ This analysis has been registered with European Network of Centres for Pharmaco-epidemiology and Pharmacovigilance (EUPAS17985) and was approved by the Anonymised Data Ethics and Protocol Transparency Committee (approval reference ADEPT 11117).

\section{Data sources}

CPRD provides anonymised data from $15 \%$ of all general practices in the United Kingdom, and data were available from 1 January 1999 through April 2012. OPCRD contains anonymised routine medical record data from $>550$ UK practices and data from 1 January 1999 to December 2012 were used for this study. The characteristics of the study population (i.e. combined CPRD and OPCRD) were compared to a population of children with asthma from OPCRD (Table 1).

\section{Inclusion and exclusion criteria}

The inclusion criteria were as follows: aged 5-12 years (consistent with the age range for children in the British Thoracic Society/Scottish Intercollegiate Guideline Network guideline) ${ }_{i}^{4}$ diagnosed asthma (by Read code, see supplement); 2 years continuous records present. The only exclusion criterion was the presence of a chronic respiratory condition, for example, cystic fibrosis. 


\section{Definitions used}

The American Thoracic Society/European Respiratory Society definition of a severe asthma attack ${ }^{27}$ was used, that is, the occurrence of any of the following: (i) an asthma-related hospital admission, (ii) an asthma-related emergency department admission or (iii) a prescription of oral corticosteroids for 3-7 days. Overall asthma control was defined as the absence of an attack (as previously defined) in the previous year and an average daily dose of $\leq 200 \mu \mathrm{g}$ salbutamol $/ \leq 500 \mu \mathrm{g}$ terbutaline. ${ }^{26}$ The GINA treatment step and dose of inhaled corticosteroid at the end of the baseline period were recorded. Peak expiratory flow was standardised using equations from Rosenthal et al. ${ }^{28}$ Blood eosinophilia was defined as total eosinophil count $>400$ cells $/ \mu \mathrm{L}$. Children were categorised as obese, overweight, healthy or thin according to the International Obesity Task Force criteria ${ }^{29}$ using data collected closest to the end of the baseline year.

\section{Statistical analysis}

Univariable logistic regression models were used to identify baseline measures of disease severity, patient demographics and comorbidities predictive of future attacks. The dichotomous variable indicating an attack during the outcome period (Yes/No) was used as the dependent variable, with each measure of disease severity, patient demographic and comorbidity as an explanatory variable. Those variables which showed an association $(p<0.05)$ with future attack were entered into a multivariable model which was step-wise reduced to produce a final list of noncollinear predictors of one or more future attacks. Two-sided statistical tests were used. Linearity was verified by categorising continuous variables, and the categorical variable was used in the final model if more appropriate than a continuous variable. Covariates were selected where the $p$ value from univariate analysis was $<0.05$; although this stringent cut off may fail to identify variables associated with the outcome, ${ }^{30}$ our large sample size mitigated against this possibility. Results were presented as ORs with $95 \%$ Cls. Standard statistical software was used (SAS version 9.3 and IBM SPSS version 22).

\section{Data availability}

The authors are not the custodians of the data and cannot make original data available but all relevant data are available from the authors. Original data are available from Clinical Practice Research Datalink (https://www. cprd.com/home/) and Optimum Patient Care (http://optimumpatientcare. org/about-us/).

\section{ACKNOWLEDGEMENTS}

We are grateful to Victoria Carter and Shaylynn Yu Hui Xin for their assistance in revising the manuscript. This analysis was funded by Respiratory Effectiveness Group

\section{AUTHOR CONTRIBUTIONS}

D.B.P. conceived the idea. A.B. analysed the data. S.W.T. wrote the first draft of the paper. All authors made meaningful contributions to the final manuscript.

\section{ADDITIONAL INFORMATION}

Supplementary information accompanies the paper on the npj Primary Care Respiratory Medicine website (https://doi.org/10.1038/s41533-018-0095-5).

Competing interests: D.B.P. has board membership with Aerocrine, Amgen, AstraZeneca, Boehringer Ingelheim, Chiesi, Mylan, Mundipharma, Napp, Novartis, Regeneron Pharmaceuticals, Sanofi Genzyme and Teva Pharmaceuticals; consultancy agreements with Almirall, Amgen, AstraZeneca, Boehringer Ingelheim, Chiesi, GlaxoSmithKline, Mylan, Mundipharma, Napp, Novartis, Pfizer, Teva Pharmaceuticals and Theravance; grants and unrestricted funding for investigator-initiated studies (conducted through Observational and Pragmatic Research Institute Pte Ltd) from Aerocrine, AKL Research and Development Ltd, AstraZeneca, Boehringer Ingelheim, British Lung Foundation, Chiesi, Mylan, Mundipharma, Napp, Novartis, Pfizer, Respiratory Effectiveness Group, Teva Pharmaceuticals, Theravance, UK National Health Service and Zentiva; payment for lectures/speaking engagements from Almirall, AstraZeneca, Boehringer Ingelheim, Chiesi, Cipla, GlaxoSmithKline, Kyorin, Mylan, Merck, Mundipharma, Novartis, Pfizer, Skyepharma and Teva Pharmaceuticals; payment for manuscript preparation from Mundipharma and Teva Pharmaceuticals; payment for the development of educational materials from Mundipharma and Novartis; payment for travel/accommodation/meeting expenses from Aerocrine,
AstraZeneca, Boehringer Ingelheim, Mundipharma, Napp, Novartis and Teva Pharmaceuticals; funding for patient enrolment or completion of research from Chiesi, Novartis, Teva Pharmaceuticals and Zentiva; stock/stock options from AKL Research and Development Ltd which produces phytopharmaceuticals; owns $74 \%$ of the social enterprise Optimum Patient Care Ltd (Australia and UK) and 74\% of Observational and Pragmatic Research Institute Pte Ltd (Singapore); and is peer reviewer for grant committees of the Efficacy and Mechanism Evaluation programme, and Health Technology Assessment. M.T. in the past 5 years has received speaker's honoraria for speaking at sponsored meetings or satellite symposia at conferences from the following companies marketing respiratory and allergy products: Aerocrine, GSK and Novartis. He has received honoraria for attending advisory panels with Aerocrine, Boehringer Inglehiem, GSK, MSD, Novartis and Pfizer. He is a member of the BTS SIGN Asthma guideline steering group and the NICE Asthma Diagnosis and Monitoring guideline development group.

Publisher's note: Springer Nature remains neutral with regard to jurisdictional claims in published maps and institutional affiliations.

\section{REFERENCES}

1. Asthma UK, facts and statistics. http://www.asthma.org.uk/asthma-facts-andstatistics.

2. Centers for Disease Control and Prevention. https://www.cdc.gov/asthma/ most recent data.htm.

3. Lozano, P., Fishman, P., VonKorff, M. \& Hecht, J. Health care utilization and cost among children with asthma who were enrolled in a health maintenance organization. Pediatrics 99, 757-764 (1997).

4. British Guideline on the Management of Asthma. https://www.brit-thoracic.org. uk/standards-of-care/guidelines/btssign-british-guideline-on-the-managementof-asthma/.

5. Bacharier, L. B. et al. Diagnosis and treatment of asthma in childhood: a PRACTALL consensus report. Allergy 63, 5-34 (2008).

6. Global Initiative for Asthma. http://ginasthma.org/2017-gina-report-globalstrategy-for-asthma-management-and-prevention/.

7. Gustafsson, P. M., Watson, L., Davis, K. J. \& Rabe, K. F. Poor asthma control in children: evidence from epidemiological surveys and implications for clinical practice. Int. J. Clin. Pract. 60, 321-334 (2006).

8. Haselkorn, T. et al. Recent asthma exacerbations predict future exacerbations in children with severe or difficult-to-treat asthma. J. Allergy Clin. Immunol. 124, 921-927 (2009).

9. Covar, R. A. et al. Factors associated with asthma exacerbations during a longterm clinical trial of controller medications in children. J. Allergy Clin. Immunol. 122, 741-747.e4 (2008).

10. $\mathrm{Wu}, \mathrm{A}$. C. et al. Predictors of symptoms are different from predictors of severe exacerbations from asthma in children. Chest 140, 100-107 (2011).

11. Fuhlbrigge, A. L., Weiss, S. T., Kuntz, K. M. \& Paltiel, A. D., CAMP Research Group. Forced expiratory volume in 1 second percentage improves the classification of severity among children with asthma. Pediatrics 118, e347-e355 (2006).

12. Ahmadizar, F. et al. Childhood obesity in relation to poor asthma control and exacerbation: a meta analysis. Eur. Respir. J. https://doi.org/10.1183/ 13993003.00766-2016 (2016).

13. Engelkes, M., Janssens, H. M., de Jongste, J. C., Sturkenboom, M. C. J. M. \& Verhamme, K. M. C. Medication adherence and the risk of severe asthma exacerbations: a systematic review. Eur. Respir. J. 45, 396-407 (2015).

14. Lieu, T. A., Quesenberry, C. P., Sorel, M. E., Mendoza, G. R. \& Leong, A. B. Computer-based models to identify high-risk children with asthma. Am. J. Respir. Crit. Care Med. 157, 1173-1180 (1998).

15. Engelkes, M. et al. Real life data on incidence and risk factors of severe asthma exacerbations in children in primary care. Respir. Med. 119, 48-54 (2016).

16. Holgate, S. et al. The Brussels Declaration: the need for change in asthma management. Eur. Respir. J. 32, 1433-1442 (2008).

17. Zeiger, R. S. et al. The association of blood eosinophil counts to future asthma exacerbations in children with persistent asthma. J. Allergy Clin. Immunol. Pract. 3, 283-287.e4 (2015).

18. Price, D. B. et al. Blood eosinophil count and prospective annual asthma disease burden: a UK cohort study. Lancet Respir. Med. 3, 849-858 (2015).

19. Robroeks, C. M. H. H. T. et al. Prediction of asthma exacerbations in children: results of a one-year prospective study. Clin. Exp. Allergy 42, 792-798 (2012).

20. Friedlander, S. L. \& Busse, W. W. The role of rhinovirus in asthma exacerbations. J. Allergy Clin. Immunol. 116, 267-273 (2005).

21. Wensley, D. \& Silverman, M. Peak flow monitoring for guided self-management in childhood asthma: a randomized controlled trial. Am. J. Respir. Crit. Care Med. 170, 606-612 (2004). 
22. Fuhlbrigge, A. L. et al. FEV(1) is associated with risk of asthma attacks in a pediatric population. J. Allergy Clin. Immunol. 107, 61-67 (2001).

23. Petsky, H. L., Kew, K. M., \& Chang, A. B. Can exhaled nitric oxide be used to adjust n with asthma? Cochrane Database Syst Rev. 2016;11:CD011439 (2016).

24. Elkout, H., Helms, P. J., Simpson, C. R. \& McLay, J. S. Changes in primary care prescribing patterns for paediatric asthma: a prescribing database analysis. Arch. Dis. Child 97, 521-525 (2012).

25. Turner, S., Thomas, M., von Ziegenweidt, J. \& Price, D. Prescribing trends in asthma: a longitudinal observational study. Arch. Dis. Child 94, 16-22 (2009).

26. Turner, S. W. et al. Initial step-up treatment changes in asthmatic children already prescribed inhaled corticosteroids: a historical cohort study. NPJ Prim. Care Respir. Med. 25, 15041 (2015).

27. Reddel, H. K. et al. An official American Thoracic Society/European Respiratory Society statement: asthma control and exacerbations: standardizing endpoints for clinical asthma trials and clinical practice. Am. J. Respir. Crit. Care Med. 180, 59-99 (2009).

28. Rosenthal, M. et al. Lung function in white children aged 4 to 19 years: 1Spirometry. Thorax 48, 794-802 (1993).

29. Cole, T. J., Bellizzi, M. C., Flegal, K. M. \& Dietz, W. H. Establishing a standard definition for child overweight and obesity worldwide: international survey. $B M J$ 320, 1240-1243 (2000).
30. Mickey, J. \& Greenland, S. A study of the impact of confounder-selection criteria on effect estimation. Am. J. Epidemiol. 129, 125-137 (1989).

(i) Open Access This article is licensed under a Creative Common Attribution 4.0 International License, which permits use, sharing adaptation, distribution and reproduction in any medium or format, as long as you give appropriate credit to the original author(s) and the source, provide a link to the Creative Commons license, and indicate if changes were made. The images or other third party material in this article are included in the article's Creative Commons license, unless indicated otherwise in a credit line to the material. If material is not included in the article's Creative Commons license and your intended use is not permitted by statutory regulation or exceeds the permitted use, you will need to obtain permission directly from the copyright holder. To view a copy of this license, visit http://creativecommons. org/licenses/by/4.0/.

(c) The Author(s) 2018 